\title{
O PENSAMENTO CEPALINO DE ONTEM E DE HOJE NA VISÃO CRÍTICA E COMPARATIVA DE ALGUNS PENSADORES
}

\author{
Wallace Moacir Paiva Lima ${ }^{1}$
}

RESUMO: Este trabalho destina-se a estudar a história da CEPAL desde a sua criação na década de 1950 até o período de reorientação da escola iniciado na década de 1990.Trata-se de uma tarefa árdua pois sua criação se deu em um mundo conturbado e fragilizado pela horrores e destruição causados pela segunda guerra. Logo, seria impossível entender a história da instituição bem como compreender suas propostas sem antes fazermos uma incursão pelo contexto histórico, político e econômico mundial e seus reflexos na região. Buscou-se neste trabalho apresentar as principais diferenças entra a CEPAL dos anos 1950 e a CEPAL dos anos 1990 e as críticas sofridas nos dois momentos da escola. Finalizaremos com um quadro comparativo que resume as principais diferenças entre a CEPAL de Presbisc e a CEPAL de Fernando Fajnzylber.

Palavras-chave: América Latina. CEPAL. Estruturalismo.

\section{INTRODUÇÃO}

A antiga CEPAL sofreu inúmeras críticas, nos anos 5o até os anos 8o. Além de todo o debate a que fizemos alusão anteriormente, diversas críticas foram dirigidas ao pensamento cepalino tanto por autores ligados à crítica do capitalismo como pelos defensores do sistema (precariamente aqui, “esquerda” e "direita”).

Já o fato de a nova abordagem da CEPAL constituir um esforço para reinserir no debate econômico a questão do desenvolvimento não a poupou de críticas, por vezes, acertadas. Essa discussão é longa e o argumento sem fim, por isso, analisa-se, a seguir apenas alguns questionamentos que parecem mais relevantes. Ainda, ao final, se se argumenta contra um julgamento excessivamente severo em relação à Nova CEPAL: igualá-la à corrente neoliberal, (ainda) hoje dominante.

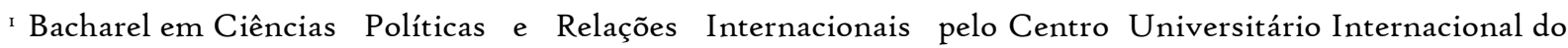
Paraná (UNINTER). E-mail: wmpaivalima@gmail.com.
} 
Neste estudo, faz-se uma análise crítica e um comparativo teórico entre as duas abordagens da CEPAL. Além disso, busca-se contrapor e discutir algumas estatísticas oficiais com determinados resultados teóricos da escola em seus dois momentos.

Ao reconstruir o pensamento da CEPAL, percebe-se o quanto de esforço está depositado nos livros. Mais do que isso, parece estar depositada ali parte das esperanças dos povos latino-americanos em um futuro melhor, menos injusto.

Por toda a trajetória intelectual da instituição, a palavra de ordem foi mudança. Mudança social e econômica, sempre subjacentes às mensagens transformadoras. Porém, tudo isso não faz apagar o caráter pragmático da CEPAL: estudar, criar e desenvolver políticas factíveis que permitissem aos países membros construir, ainda que lentamente, seu desenvolvimento. Dessa maneira, era impossível a instituição não estar atenda a cada momento histórico que rodeava e, por isso mesmo, não matizar, mas até alterar suas propostas, conforme a urgência e a transformação dos países (RODRIGUEZ et al., 1995).

Destarte, as diferenças entre a Antiga CEPAL e a nova CEPAL devem ser entendidas além da análise estritamente teórica. Sua compreensão tem de contextualizar suas contribuições e fracassos, trazendo à tona não apenas as diferenças entre elas, mas também, e talvez principalmente, o que de melhor foi produzido pelo pensamento econômico latino-americano no período. Essa foi a preocupação nos capítulos anteriores. Nos próximos tópicos serão salientadas as diferenças entre as abordagens cepalinas, suas possibilidades explicativas, sem, contudo, deixar de perceber os momentos em que cada uma teve e tem função especial.

\section{O BALANÇO DOS PRIMEIROS DEZ ANOS DA CEPAL E AS PRINCIPAIS CRÍTICAS À TEORIA DO SUBDESENVOLVIMENTO}

As transformações ocorridas em algumas economias da América Latina ao longo da década de 50 influenciaram o pensamento cepalino. A indústria não era mais um ideal e muitas empresas estrangeiras haviam se fixado no subcontinente.

Apesar disso, a instituição manteve sua influência e tornou-se um fórum de discussão, crítico ao modelo de industrialização em curso. Os principais problemas assentavam-se na incapacidade de essa industrialização incorporar a maioria da população 
aos frutos do progresso técnico. $\mathrm{O}$ aprendizado da casa em relação a dinâmica do emprego indicava que este dependia não apenas da industrialização, mas de uma mudança na estrutura social, redistribuição de renda e reforma agrária (BIELSCHOWSKY, 1998).

Outro problema identificado nos primeiros anos da instituição foi a ausência de poupança para custear a industrialização por meio da substituição da importação. A tecnologia importada impunha escalas de produção ajustadas às necessidades dos países desenvolvidos que por sua vez era bem diferente da realidade latino-americana. Esta possuía um mercado interno menor e mais restrito. Assim, para um dado volume de produto a ser substituído a quantidade de capital exigido era muito grande e o emprego gerado relativamente pequeno. De acordo com Maria Conceição Tavares,

\footnotetext{
A instalação de unidades industriais para produzir internamente bens de consumo final que antes se importavam tende a expandir o mercado interno desses mesmos bens, não só pelo próprio crescimento de renda decorrente do processo de investimento, como pela inexistência de restrições internas análogas às que limitavam as importações dos mesmos. Por outro lado, a sua produção apenas substitui uma parte do valor agregado, anteriormente gerado fora da economia. Em conseqüência, a demanda derivada por importações de matéria prima e outros insumos cresce rapidamente tendendo a ultrapassar as disponibilidades de divisas (TAVARES apud BIELSCHOWSKY (200o, p. 232)
}

Ou seja, a própria capacidade de exportação e o mercado externo limitam o processo substitutivo. Tudo isso resulta, segundo a autora, em uma estagnação dos setores exportadores que vai refletir diretamente na capacidade de importar bens e equipamentos para a indústria. Sendo assim, os laços de dependência ainda existem, mas agora com uma nova roupagem, além de resultar em um novo dualismo.

\section{2.r. O desencontro entre teoria e prática}

A CEPAL quando fez o planejamento do modelo aqui apresentado, levou em consideração o crescimento econômico como determinante dos níveis de distribuição de renda, havendo, portanto, um desencontro entre teoria e técnica (RODRIGUES, 198I).

Havia uma incompatibilidade entre as pretensões de desenvolvimento e as técnicas de ação. Até 1980 acreditava-se que o desenvolvimento econômico superaria os problemas de curto prazo, ignorados pela CEPAL. No entanto, nem o crescimento a longo prazo levou ao controle dos desequilíbrios macroeconômicos de curto prazo, tão pouco o processo de industrialização foi capaz de alavancar os demais setores da sociedade. 
A crítica desenvolvida pela própria CEPAL observava que a industrialização havia superado a situação de quase enclave do setor exportador e alcançado certa autonomia interna, crescendo a partir de suas próprias forças. Contudo, isso não significou uma maior irradiação dos frutos do seu progresso técnico junto às atividades e regiões 'atrasadas'. Isto é, o modelo industrial implicou uma transformação parcial, determinada pelo alcance do progresso técnico no setor industrial e nas atividades complementares (PINTO, 1965), deixando grande parte do corpo econômico à margem das transformações.

A estrutura de posse da terra era problemática para a CEPAL. Latifúndios e pequenas propriedades concorriam para expulsão de mão-de-obra do campo. Nas grandes propriedades, as enormes quantidades de terra dificultavam sua plena utilização dado o capital necessário. Além disso, tendiam a mecanizar as tarefas agrícolas, absorvendo menos mão-de-obra. Já os minifúndios careciam de capacidade de acumulação e de modificação de técnicas de cultivo, tornando-se difícil aumentar a produtividade da terra e da força de trabalho. Com isso, o campo não conseguia reter a população que nele trabalhava (RODRIGUEZ, I98I).

Em 1963, em seu texto La dinâmica del desarrollo latinoamericano, Prebisch propõe uma nova agenda que busque alterar a estrutura social e a distribuição de renda, sobretudo por intermédio da reforma agrária. Desta forma deveriam ser abertas várias frentes: maior investimento e melhor utilização do capital existente, aplicação do capital em atividades absorventes de mão-de-obra etc. tudo objetivando aumentar a relação produto-capital (PINTO, 1965).

\section{PENSAMENTO NEO-ESTRUTURALISTA CEPALINO: A “NOVA CEPAL”}

A CEPAL, que sempre percebeu em seu pensamento as questões históricas da região, viu-se mais uma vez frente a uma grande transformação. O mundo modificava-se e seus reflexos sobre os países da região eram sentidos em doses cada vez mais dramáticas. Desse modo, para uma instituição que pretendia pensar o desenvolvimento regional baseado na realidade das nações latino-americanas, era inevitável a alteração de idéias e enfoques. O chamado neo-estruturalismo vem responder exatamente a essa demanda: um 
novo enfoque para o desenvolvimento econômico da região paralisada ou semiestagnada por uma década de crise.

\subsection{A nova Visão da CEPAL}

A CEPAL, preocupada com o lado pragmático de seus estudos, alterou o foco de suas pesquisas. As questões conjunturais eram de tal monta sufocantes, que os pesquisadores da casa se viram obrigados a voltar os olhos para o curto prazo. Propostas que condenavam os ajustes recessivos impostos aos países latino-americanos, formas diferentes de enxergar e combater os processos inflacionários, etc. foram o mote do período para a casa.

A proposta da Nova CEPAL nasce, portanto, da necessidade de retomar o debate sobre desenvolvimento econômico, sem perder de vista a crítica e a superação do pensamento da casa nos so e 6o (BIELCHOWSKY, 1998). Um pensamento enfraquecido que via no processo de substituição de importações o caminho para o desenvolvimento, através da industrialização e do papel fundamental do Estado. Para os economistas da casa, haviam sido fatais para o antigo pensamento o elevado protecionismo, a baixa competitividade internacional e a coordenação e hierarquização de metas sociais. Contudo, talvez o mais importante fosse reagir à ortodoxia que viabilizava o pagamento da dívida externa através de exportações de recursos naturais e baixos salários, com reinado do mercado, diminuição do Estado e questionamento da eficiência da industrialização latinoamericana.

Para realizar essa tarefa, os economistas cepalinos posicionaram-se, na opinião de Bielschowsky (1998), intermediariamente entre os liberais e os opositores da ortodoxia econômica ${ }^{2}$. $\mathrm{Na}$ verdade, porém, o novo pensamento da instituição não se opôs às reformas preconizadas pelos liberais, tendendo mesmo a apoiá-las. A tática parece ter sido não

\footnotetext{
2 Este programa parte do reconhecimento de que este conjunto de reformas liberalizantes pode ter influência positiva sobre o processo de crescimento, desde que seja bem conduzido. Mas , por outro lado, a 1 investigação cepalina exige o reconhecimento de que na América Latina justifica-se ainda um conjunto de políticas públicas de suporte ao desenvolvimento em função das peculariedades das estruturas produtivas, da organização de mercados e, não menos importante, da configuração das sociedades dos países da região (BIELCHOWSKY, 200o, p. 68).
} 
resistir, com a intenção de subordinar essas mesmas reformas liberais à apreciação estratégia que passasse a maximizar benefícios e minimizar as deficiências de médio e longo prazos. Para Bielschowsky (1998, p. 68), a CEPAL tentava recuperar a agenda de análises e de políticas de desenvolvimento, adaptando-a aos novos tempos de abertura e globalização. Desta forma, o novo pensamento buscava lançar-se novamente na liderança dos processos de reformas por que passaria a América Latina, propondo uma forma diferente de atuação do Estado.

De acordo com Sampaio Jr. (1997), havia frustração com os resultados da industrialização e o choque com a violência da reação contra-reformista na América Latina. Por isso, ainda segundo ele,

\begin{abstract}
As proposições a favor de reformas estruturais sofreram abrupto giro de perspectiva que inverteu completamente seu significado. Ao invés de adequar o modo de organização da economia e da sociedade à necessidade de colocar a acumulação de capital a serviço do desenvolvimento nacional, o neo-reformismo da CEPAL passou a defender a necessidade de subordinar o arranjo econômico e social às exigências de uma reinserção dinâmica no comércio internacional (SAMPAIO JR, 1997, p. 42).
\end{abstract}

O diagnóstico da CEPAL para a América Latina, no início dos anos 9o, não indicava um bom cenário. Recessão, exportação líquida de recursos, inflação, inadequação exportadora, obsolescência no parque produtivo e da infraestrutura e, por fim, pesados custos sociais dos ajustes econômicos. Resumindo, o fim dos anos 80 não significaram apenas crise, mas sim o fim do padrão precedente de desenvolvimento do subcontinente (SAMPAIO JR, 1997)

A industrialização, embora questionada e revista, ainda aparece como o caminho a ser trilhado na busca do desenvolvimento, constituindo o eixo da transformação produtiva posto ser ela portadora da incorporação e difusão do progresso técnico (CEPAL, 1990). Foi partindo desse ponto de vista que a CEPAL propôs uma nova mensagem transformadora: transformar produtivamente a região agindo simultaneamente em favor de melhores níveis de igualdade social. A idéia era vencer a longa crise dos anos 80 , através da continua e deliberada incorporação de progresso técnico a fim de elevar a competitividade internacional das economias locais, implicando, por sua vez, uma nova e diferente inserção mundial (RODRIGUEZ et al., 1995). 
O estudo que se inicia oficialmente essa nova etapa chamou-se Transformación Productiva com Equidad e apareceu no período de sessões de abril de 1990, sob a coordenação de Fernando Fajnzylber. Embora reclamando a tradição cepalina, o estudo mantém pouco da referência original dos anos so e 6o. Dentro dele, embora o foco mantenha-se sobre a análise da inserção internacional, a compreensão das condicionantes estruturais do crescimento e do progresso técnico e mesmo na relação centro-periferia, não obstante parece haver, quanto às relações entre eles e o mercado de trabalho, emprego e distribuição de renda, assim como as possibilidades de ação estatal, uma distância significativa nos dois momentos da escola (RODRIGUEZ et al., 1995).

\subsection{O estudo de Fernando Fajnsylber}

Evoluído desses questionamentos, Fernando Fajnsylber realizou os estudos mais importantes da época. Sua abordagem, embora nova, não fugiu de alguns elementos caros à tradição cepalina: a) análise da importância do progresso técnico; b) o problema da concentração fundiária, condicionando a distribuição de renda e, deste modo, o padrão de consumo; c) Baixa capacidade de poupança e investimento na região.

Foi entorno dessas imagens - uma revolução tecnológica em andamento e globalização - que a CEPAL passou articular seus recentes conceitos e idéias. Diante do diagnóstico, a nova CEPAL reelaborou sua abordagem, matizando relações e conceitos, enfatizando processos e deixando em segundo lugar parte do que foi a teoria da antiga CEPAL (BIELCHOWSKY, 1998).

Em La Industrialización Trunca de América Latina, Fajnsylber percebeu a fraqueza do processo de industrialização latino-americano. Segundo ele, embora a nova ordem mundial implantada com a Guerra Fria tivesse permitido aos países da região uma nova dinâmica econômica, apoiada na demanda interna e no investimento, o fez baseado na liderança e no modelo das multinacionais que se espalhavam pelo mundo. Na América latina, essas empresas têm um papel primordial, pois terminaram por direcionar nossa industrialização em detrimento de uma política de desenvolvimento elaborada por agentes nacionais. $\mathrm{O}$ resultado é que se reproduziram tendências produtivas, tecnológicas e de consumo 
funcionais para os países avançados, mas inadequadas aos países da América Latina (BIELCHOWSKY, 1998).

A adoção desse padrão industrial na América Latina exigia crescentes investimentos e, para tal, os bens de capital deveriam ser baratos, mesmo que a custa de importações, porém, é preciso ressaltar que, se os gastos com os bens de capital melhoravam a produtividade das economias, por outros, impedia o desenvolvimento autônomo do país.

Por tudo isso, com o desvio da demanda e com a impossibilidade de desenvolvimento técnico autônomo, o resultado não poderia ser outro: uma indústria de bens de capital fraca, incapaz de investir fortemente em tecnologia e, tão grave quanto, incapaz de fechar o "fluxo circular da renda" gerada no país.

\section{A ANTIGA CEPAL NA VISÃO DA ESQUERDA E DA DIREITA}

Os críticos de direito viam as idéias da CEPAL como construções ideológicas que deveriam ser postas a nu. O próprio conceito de centro e periferia era visto como uma abstração simplificada, de pouco valor analítico, que se baseava na idéia de que a divisão internacional do trabalho não cumpriria as promessas contidas na "Teoria do Comércio Internacional". Para eles, a Antiga CEPAL teria subestimado o transbordamento do dinamismo do centro, particularmente dos EUA. Mais, não seria correto supor que os países chamados periféricos exportassem apenas bens primários e os do centro, bens industrializados (OLIVEIRA, 1972).

As idéias da CEPAL também foram criticadas no que parecia ser uma acusação contra o centro, responsável pelas dificuldades sofridas por outros povos. É uma opinião que, embora exagerada, não é de todo descabida. Não é descabida porque, ao apontar a questão das relações de economias desiguais entre centro e periferia, a questão do desenvolvimento pareceu centrar-se na oposição entre nações (OLIVEIRA, 1972). Porém, uma análise dos textos cepalinos mostra que é excessivo dar à instituição o papel de acusador dos países ricos. A Antiga CEPAL enxergava nas condições de heterogeneidade dentro da periferia as causas da perpetuação do caráter subdesenvolvido dos países. 
Mesmo assim, a tendência à deterioração dos termos de troca foi provavelmente o lado mais criticado das idéias da Antiga CEPAL e também o mais mal interpretado. Primeiro, simplesmente duvidou-se de que tenha havido deterioração dos preços relativos dos bens primários ao longo do tempo. E para isso três argumentos foram usados: a) alguns bens primários tiveram melhora na sua relação de troca; b) os dados utilizados pela CEPAL são problemáticos. (OLIVEIRA, I972)

Quanto ao item (a), poucas palavras cabem. Mais de uma vez, a própria CEPAL enfatizou que havia bens primários particulares que possuíam elasticidade renda da demanda superior à unidade e o exemplo mais famoso era o petróleo. Quanto ao segundo, item (b), o problema é mais complexo. A CEPAL, ao realizar suas estimativas, utilizou dados FOB para exportação e CIF para importação inglesa durante o período de 1870 a 1940. Nessa época, os fretes tiveram importante queda em seus custos, tornando menos significativas as diferenças entre os preços FOB e CIF. Por isso, argumentaram os críticos, é natural que se estime aparente queda relativa nos custos de importação da Inglaterra, mas, na verdade, o que se viu foi uma redução no valor do frete. Aqui, a crítica é devida e realmente a CEPAL não elaborou qualquer estudo que corroborasse sua tese (RODRIGUEZ, 198I).

No entanto, discordamos de Rodriguez pois os textos da CEPAL analisados ao longo deste trabalho demonstram argumentos contundentes quanto a perda no intercâmbio entre centro e periferia. Até porque segundo a teoria das vantagens comparativas os resultados alcançados entre estes países (sul e norte) seria o mesmo o que não corresponde com a verdade. Os bens exportados pelos paises desenvolvidos têm maior valor agregado e absorvem maior tecnologia e sua demanda cresce a medida que ocorre aumento de salário na população, $\mathrm{O}$ mesmo não se pode dizer para os produtos exportados pelos países periféricos. Os produtos agrícolas e primários tinham pouco ou quase nenhum valor agregado, não exigiam tecnologia moderna, e quando esta era usada se fazia necessário a redução dos empregados visto que as máquinas substituíam parte da mão-deobra e por fim eram limitados a capacidade de consumo de cada família podendo também ser substituído, como de fato aconteceu, por produtos similares ou sintéticos. Desta forma, é nossa opinião que as premissas de Prebisch estavam corretas. 
O acentuado papel dado ao Estado no Pensamento da CEPAL também sofreu críticas severas e nem sempre razoáveis. Receavam-se alguns que o planejamento das ações econômicas, a produção de bens, a apropriação e distribuição do excedente econômico feitas pelo Estado poderiam levar a um estatismo socializante, burocrático e ineficaz. Todavia, dados os diagnósticos cepalinos, pouco restava a não ser dotar o órgão mais representativo do país a fim de que tomasse as rédeas do sistema e superasse suas mazelas. Além disso, a defesa da intervenção estatal se fez em nome da manutenção e do crescimento do próprio capitalismo na periferia.

É importante destacar que apesar das diferenças político-econômicas, sociais e estruturais , o Estado foi o motor da industrialização dos países centrais e ainda o é. $\mathrm{O}$ modelo liberal proclamado por estes países não é adotado inteiramente por eles, pois a história demonstra a relevância de um agente nacional para defender os interesses da nação.

\section{4.r. A Nova CEPAL e seus críticos}

O primeiro aspecto que levanta algumas suposições da nova CEPAL seria a estratégia de longo prazo, conforme aponta Rodriguez et al (1995, p. IOI):

\footnotetext{
Supõe a possibilidade de um conjunto "catching-up" do progresso técnico por parte das economias latino-americanas que adotem suas recomendações, ou, em outras palavras, a possibilidade de participar da revolução tecnológica em curso.
}

Porém, essa suposição revela-se estrategicamente ambígua: afinal, ela cabe perfeitamente tanto dentro do desenvolvimento autônomo quanto do associado. Buscar reduzir ou mesmo superar o atraso tecnológico das economias latino-americanas pode ser feito tanto através do desenvolvimento de tecnologia própria como também na limitação de padrões dos países centrais. Tal diferenciação é muito importante, pois leva os agentes sociais não só a projetos e ações diferenciadas, mas implica decidir qual trajetória histórica se pretende tomar, assim como os riscos inerentes a cada uma delas. Enfim, o problema é que a estratégia não se revelaria tão geral quanto se pretendia. 
O que se questiona é se as oportunidades terão amplitude suficiente para sustentar um crescimento econômico do tipo extrovertido, ainda mais de a discussão recair sobre países grandes, como Brasil e México (RODRIGUEZ et al., 1995).

Contudo, mesmo com a Nova CEPAL afirmando os problemas da heterogeneidade, não passa despercebido por Sampaio Jr (1997) que, ao deixar de lado o enfoque da inflação estrutural, a nova estratégia da instituição praticamente abandona os conflitos distributivos existentes nas economias periféricas. A necessidade de redução heterogeneidades estruturais parecem passar do primeiro plano, como parte da estratégia de desenvolvimento econômico, para um segundo plano.

A resposta nos textos da CEPAL não satisfaz. Fala-se em um trabalho de longo prazo, baseado na educação, treinamento e legalização da economia informal, aumentando sua produtividade e a renda de quem nela trabalha. Porém, mesmo a CEPAL admite que o subemprego e a informalidade urbana persistam longamente. Diante disso, Rodriguez et al (1995, p. 103) é direto ao afirmar que,

Resta então definir se a tendência ao desemprego aberto e, sobretudo, a presença de grandes contingentes de mão-de-obra subempregada são compatíveis com o alcance de padrões de equidade adequados ou em contínua melhora.

$\mathrm{Na}$ verdade, do ponto de vista teórico, crê Rodriguez et al (1995), é um desequilíbrio que compromete a abordagem da Nova CEPAL: excessiva ênfase ao progresso técnico e seus efeitos positivos sobre o crescimento econômico e a reinserção internacional; e insuficiente análise da dinâmica perversa da heterogeneidade e do subemprego, assim como de medidas para superá-los. E de fato a análise do texto TPE nos permite relembrar um erro cometido pela velha CEPAL, o desencontro entre teoria e prática uma vez que Fajnsylber não traz propostas claras para a superação dos problemas sociais da região,

\subsection{As principais diferenças}

Para os novos economistas da casa, a economia sofria de menor produtividade comparada, levando a menores níveis de renda em relação aos centros desenvolvidos. Ao mesmo tempo, os padrões de consumo eram marcados pela sofisticação, uma característica que tendia a agravar-se com o progresso técnico e a importação de padrões culturais. $\mathrm{Ou}$ 
seja, o tipo e o nível elevado de consumo tendiam a problematizar a acumulação e a reduzir seu ritmo, criando um quadro de acumulação lenta, que não conseguia acompanhar a expansão da PEA. Em outras palavras, havia insuficiência dinâmica (CEPAL, 1990).

Entretanto, para a Nova CEPAL não havia solução de curto prazo. O objetivo básico da competitividade autêntica colocava a incorporação do progresso técnico na condição de fundamento das mudanças. As mesmas mudanças que documentos da casa reconheciam comprometer a absorção rápida de mão-de-obra, por exemplo. Por esse motivo, a proposta da Nova CEPAL objetivava a inteira transformação produtiva do espaço econômico latino-americano. Tal modernização não se restringiria a empresas e processos, mas ia além, buscando a integração e a complementaridade entre os setores, assim como, dentro de um ambiente competitivo, o espalhamento da lógica industrial para toda a economia (CEPAL, 1990).

A tabela a seguir tenta resumir as duas CEPAL

Tabela I - Comparativo das Duas CEPAL

\begin{tabular}{|c|c|c|}
\hline & ANTIGA CEPAL & NOVA CEPAL \\
\hline $\begin{array}{c}\text { CONCEITO DE } \\
\text { DESENVOLVIMENTO }\end{array}$ & $\begin{array}{c}\text { Elevação das condições de vida da } \\
\text { população, por meio de aumento } \\
\text { de suas remunerações, } \\
\text { pressupondo, principalmente, } \\
\text { aumento da produtividade, } \\
\text { vinculada à aceleração da taxa de } \\
\text { acumulação de capital. Confunde- } \\
\text { se com crescimento econômico, } \\
\text { conseguido através da } \\
\text { industrialização. }\end{array}$ & $\begin{array}{c}\text { Crescer, melhorar a } \\
\text { distribuição de renda,e a } \\
\text { democracia, buscar menor } \\
\text { dependência, alcançar a } \\
\text { sustentabilidade ambiental e a } \\
\text { melhoria da qualidade de vida } \\
\text { da população. Tudo vinculado a } \\
\text { uma inserção mais competitiva } \\
\text { à economia internacional. }\end{array}$ \\
\hline $\begin{array}{l}\text { VISÃO DA } \\
\text { ECONOMIA } \\
\text { MUNDIAL }\end{array}$ & $\begin{array}{l}\text { Sistema centro-periferia com } \\
\text { especialização dos pólos. }\end{array}$ & $\begin{array}{l}\text { Processo de globalização da } \\
\text { economia; disputa pelo } \\
\text { mercado de bens industriais de } \\
\text { elevado conteúdo tecnológico. }\end{array}$ \\
\hline $\begin{array}{l}\text { OBSTÁCULO } \\
\text { FUNDAMENTAL }\end{array}$ & $\begin{array}{l}\text { Elevar a taxa de acumulação de } \\
\text { capital, posto que a mão-de-obra } \\
\text { não é o elemento constrangedor. }\end{array}$ & $\begin{array}{l}\text { Obter o domínio tecnológico e } \\
\text { alcançar competitividade } \\
\text { internacional. }\end{array}$ \\
\hline EMPREGO & $\begin{array}{c}\text { A questão do emprego é } \\
\text { fundamental. Sem a redução do } \\
\text { desemprego aberto e disfarçado, } \\
\text { não seria possível o } \\
\text { desenvolvimento nem o } \\
\text { crescimento equilibrado. }\end{array}$ & $\begin{array}{c}\text { Embora importante, a } \\
\text { admissão de que o desemprego } \\
\text { e o subemprego permaneceriam } \\
\text { por muitos anos mostra que a } \\
\text { preocupação agora está mais } \\
\text { centrada na competitividade e } \\
\text { na distribuição de renda via } \\
\text { políticas compensatórias. }\end{array}$ \\
\hline
\end{tabular}




\begin{tabular}{|c|c|c|}
\hline EQUIDADE & $\begin{array}{l}\text { Tende a resolver-se com o avanço } \\
\text { do processo de industrialização. }\end{array}$ & $\begin{array}{l}\text { a) Para o setor competitivo, } \\
\text { ocorre via integração à } \\
\text { economia mundial, em um } \\
\text { "circulo virtuoso acumulativo"; } \\
\text { b) Para os segmentos sociais } \\
\text { não integrados, políticas } \\
\text { sociais. }\end{array}$ \\
\hline ESTADO & $\begin{array}{l}\text { Papel de direção e liderança no } \\
\text { processo de industrialização; } \\
\text { realizador de importantes } \\
\text { investimentos }\end{array}$ & $\begin{array}{l}\text { Papel articulador e gerador de } \\
\text { consensos sócio-políticos; } \\
\text { importante participação na } \\
\text { geração de base sistêmica de } \\
\text { competitividade; papel } \\
\text { fundamental no campo social; } \\
\text { manutenção dos equilíbrios } \\
\text { macroeconômicos. }\end{array}$ \\
\hline $\begin{array}{c}\text { CAPITAL } \\
\text { ESTRANGEIRO }\end{array}$ & $\begin{array}{l}\text { Participação necessariamente } \\
\text { transitória e complementar. }\end{array}$ & $\begin{array}{l}\text { Participação desejada se houver } \\
\text { mecanismo de transferência de } \\
\text { tecnologia; não deve ser } \\
\text { principal financiados da } \\
\text { transformação produtiva com } \\
\text { equidade social. }\end{array}$ \\
\hline $\begin{array}{c}\text { EIXO DO } \\
\text { CRESCIMENTO }\end{array}$ & Mercado Interno & $\begin{array}{l}\text { Mercado interno e externo } \\
\text { reforçando-se através da } \\
\text { competitividade e expansão das } \\
\text { exportações. }\end{array}$ \\
\hline REFORMA AGRÁRIA & $\begin{array}{l}\text { Tentativa de evitar problemas de } \\
\text { êxodo rural, posto que, na } \\
\text { agricultura, o problema surgia da } \\
\text { estrutura de posse da terra, pois } \\
\text { latifúndio e pequena propriedade } \\
\text { concorriam para expulsão de mão- } \\
\text { de-obra do campo. }\end{array}$ & $\begin{array}{l}\text { Embora a aparente semelhança, } \\
\text { a Nova CEPAL parece mais } \\
\text { preocupada com a redução do } \\
\text { poder político e econômico das } \\
\text { elites, posto que a estrutura da } \\
\text { propriedade atual contribuísse } \\
\text { significativamente para o } \\
\text { atraso institucional e } \\
\text { tecnológico. }\end{array}$ \\
\hline ELITES NACIONAIS & $\begin{array}{l}\text { Não parece perceber como } \\
\text { obstáculo importante a ação } \\
\text { conservadora das elites às } \\
\text { mudanças induzidas pelo } \\
\text { desenvolvimento. }\end{array}$ & $\begin{array}{l}\text { Necessidade de transformação } \\
\text { da estrutura agrária a fim de } \\
\text { impedir o surgimento de uma } \\
\text { dominação na qual setores } \\
\text { tradicionais desenvolvam } \\
\text { flexibilidade para absorver e } \\
\text { distorcer processos de } \\
\text { modernização. }\end{array}$ \\
\hline $\begin{array}{l}\text { INDUSTRIALIZAÇÃO } \\
\text { ESTIMULADA }\end{array}$ & $\begin{array}{c}\text { Traz progresso técnico e resolve a } \\
\text { problemática da tendência } \\
\text { estrutural ao } \\
\text { subdesenvolvimento. }\end{array}$ & $\begin{array}{l}\text { Transformação produtiva e o } \\
\text { eixo difusor do progresso } \\
\text { técnico, mas não é condição } \\
\text { suficiente para resolver } \\
\text { problemas estruturais. }\end{array}$ \\
\hline PROGRESSO & Está profundamente ligado ao & Tal tecnologia não mais estaria \\
\hline
\end{tabular}




\begin{tabular}{|c|c|c|}
\hline TÉCNICO & $\begin{array}{l}\text { conceito de desenvolvimento, na } \\
\text { medida em que permite elevação } \\
\text { da produtividade e das } \\
\text { remuneração. }\end{array}$ & $\begin{array}{l}\text { apenas nos bens de capital, mas } \\
\text { também nos processos } \\
\text { gerenciais e organizacionais e, } \\
\text { portanto, não seria exógeno à } \\
\text { empresa. }\end{array}$ \\
\hline ESPECIALIZAÇÃO & $\begin{array}{c}\text { Conotação negativa: o objetivo é } \\
\text { construir uma economia } \\
\text { diversificada. }\end{array}$ & $\begin{array}{l}\text { Especialização em setores } \\
\text { selecionados pode ser } \\
\text { altamente desejável, } \\
\text { principalmente para países } \\
\text { pequenos. }\end{array}$ \\
\hline FINANCIAMENTO & $\begin{array}{c}\text { Transferência de recursos do setor } \\
\text { primário-exportador; tributação e } \\
\text { controle sobre importações } \\
\text { supérfluas; Estado. }\end{array}$ & $\begin{array}{l}\text { a) Geração de poupança } \\
\text { interna. } \\
\text { b) Solução da dívida externa. }\end{array}$ \\
\hline $\begin{array}{c}\text { INSERÇÃO } \\
\text { INTERNACIONAL I }\end{array}$ & $\begin{array}{l}\text { Mais importante, na verdade, era } \\
\text { o rompimento com a antiga forma } \\
\text { de inserção subordinada. Uma } \\
\text { nova inserção internacional não } \\
\text { seria tão relevante para tirar os } \\
\text { países da região do } \\
\text { subdesenvolvimento. As forças } \\
\text { progressistas teriam de nascer } \\
\text { internamente. }\end{array}$ & $\begin{array}{l}\text { A nova inserção internacional } \\
\text { seria importante sim, na } \\
\text { medida em que tira os países do } \\
\text { isolamento, quando uma rápida } \\
\text { transformação tecnológica está } \\
\text { em andamento. E mais, se bem } \\
\text { conduzida, a abertura traria } \\
\text { aprendizado da competição, } \\
\text { capaz de tornar os produtos } \\
\text { latino-americanos mais } \\
\text { interessantes no exterior. }\end{array}$ \\
\hline $\begin{array}{c}\text { INSERÇÃO } \\
\text { INTERNACIONAL } 2\end{array}$ & $\begin{array}{l}\text { A inserção no mercado } \\
\text { internacional se faria através de } \\
\text { uma industrialização competidora } \\
\text { que enfrentaria nações ricas no } \\
\text { mercado mundial. Enfim, parte } \\
\text { mais enfaticamente de questões } \\
\text { internas para aí sim falar em nova } \\
\text { inserção mundial. }\end{array}$ & $\begin{array}{l}\text { A nova inserção dos países se } \\
\text { faria através da incorporação de } \\
\text { tecnologia e do aumento do } \\
\text { coeficiente de exportação, } \\
\text { competindo sim, mas através } \\
\text { de nichos e da colaboração com } \\
\text { o capital estrangeiro. }\end{array}$ \\
\hline $\begin{array}{l}\text { VANTAGENS } \\
\text { COMPARATIVOS E } \\
\text { COMPETITIVAS }\end{array}$ & $\begin{array}{l}\text { Critica à teoria tradicional do } \\
\text { comércio internacional. }\end{array}$ & $\begin{array}{l}\text { Construção de vantagens } \\
\text { competitivas a partir da } \\
\text { dinamização das vantagens } \\
\text { comparativas. }\end{array}$ \\
\hline $\begin{array}{c}\text { SUSTENTABILIDADE } \\
\text { AMBIENTAL }\end{array}$ & Não é alvo de preocupações & $\begin{array}{c}\text { Fator necessário para a } \\
\text { qualidade de vida e obtenção de } \\
\text { competitividade autêntica. }\end{array}$ \\
\hline BASE TEÓRICA & $\begin{array}{c}\text { O pensamento da CEPAL altera, } \\
\text { mas não supera a teoria } \\
\text { tradicional. }\end{array}$ & $\begin{array}{l}\text { De inspiração neo- } \\
\text { estruturalista. }\end{array}$ \\
\hline
\end{tabular}

Fonte: Tabela desenvolvida através da análise de Rodriguez et al.,(1995); CEPAL (1990); BIELSCHOWSKY (2000) e MELLO (1997).

Ao examinarmos a tabela acima, parece que a Nova CEPAL oferece, em alguns pontos, maior compreensão da realidade. Todavia, talvez pela própria complexidade das 
novas variáveis, há uma perda da capacidade de alinhavar uma teoria lógica e coerente. Aparentemente, se a Antiga CEPAL possuía uma visão clara, uma teoria positiva com começo, meio e fim, assim era possível porque sua abordagem se centrava em um estudo, que, mesmo complexo, possuía variáveis tratáveis, geradoras de diagnósticos passíveis de se tornarem políticas econômicas.

Estava para ela subentendido que as forças sociais, inclusive as elites, principalmente a industrial, responderiam positivamente aos esforços industrializantes, através da formação de um empresariado independente, nacional e capaz de desenvolver aqui a cultura capitalista competitiva em oposição à rentista (FURTADO, 1998).

Entretanto, nos anos 6o, já era perceptível que as forças industrializantes "tendiam a aliar-se ao latifundismo e à direita ideológica contra o fantasma das organizações sindicais nascentes" (FURTADO, 1998, p. 20).

Dessa percepção e da crítica, torna-se quase impossível a uma nova abordagem do desenvolvimento econômico latino-americano alhear-se das questões políticas internas e externas à região. Todavia, a necessidade de tratar esse novo mundo de variáveis exige a elaboração de abordagens mais gerais e menos aplicadas. Ao tentar mantê-las restritas ao campo econômico, por motivo de aceitabilidade ou aplicabilidade, torna o terreno pantanoso e, por vezes desconexo. Parece que essa foi a armadilha em que a Nova CEPAL se viu presa. Ciente dos novos problemas levantados pela teoria da dependência, e precisando para entrar no debate, que sua teoria fosse aceita, a instituição tentou formatar um campo teórico abrangente (com questões de política, pressupondo as informações da teoria da dependência), mas restrito a variáveis econômicas, digeríveis aos economistas. Não parece difícil de imaginar que surgiriam aqui e ali problemas no corpo da teoria (FURTADO, 1998).

Por tudo isso, não podemos passar ao largo de suas fraquezas. Se a grande força da teoria dos tempos de Prebisch fez os olhos se voltarem para uma problemática nova na época, também o fez de modo limitado, incapaz de perceber as possibilidades e as implicações das alianças políticas entre atores sociais aparentemente opostos. Toda sua preocupação com a independência economia da nação não enfrentou a questão das classes 
sociais, mascarando e impedindo a construção de uma teoria sobre o capitalismo em nossa realidade (MELLO, 1997, OLIVEIRA, 1972).

As comparações acima já nos permitem algumas ilações e os estudos dos capítulos anteriores completam o quadro. Porém, para finalizar a comparação entre as duas CEPAL o que as abordagens previam? Para facilitar a observação, aponta-se duas previsões separadas por temas e abordagens, de maneira semelhante à feita antes na tabela a seguir.

\section{Tabela 2 - Previsões Cepalinas}

\begin{tabular}{|c|c|c|}
\hline DESENVOLVIMENTO & $\begin{array}{c}\text { ANTIGA CEPAL } \\
\text { Acreditava que o } \\
\text { desenvolvimento } \\
\text { viria com a } \\
\text { industrialização. }\end{array}$ & $\begin{array}{c}\text { O desenvolvimento exige que uma } \\
\text { coleção de fenômenos caminhe juntos } \\
\text { no sentido de crescer, melhorar a } \\
\text { distribuição de renda, evoluir na } \\
\text { democracia, sustentabilidade } \\
\text { ambiental e melhor inserção } \\
\text { competitiva na economia } \\
\text { internacional. }\end{array}$ \\
\hline Equidade & $\begin{array}{c}\text { Tende a resolver-se } \\
\text { com o avanço do } \\
\text { processo de } \\
\text { industrialização. }\end{array}$ & $\begin{array}{c}\text { Não há solução de curto prazo. São } \\
\text { necessárias políticas muito firmes, } \\
\text { inclusive assistenciais. }\end{array}$ \\
\hline
\end{tabular}

Fonte: Tabela desenvolvida através da análise de Mello (1997) e Furtado (1998).

\section{CONSIDERAÇÕES FINAIS}

Em todo o trabalho, teve-se a sensação de que a CEPAL tentou ser agente do seu tempo. Mesmo a atual abordagem, ao nascer, refletia as mudanças que ocorriam no mundo da época. Essas mesmas modificações, naturalmente, metamorfosearam o capitalismo. $\mathrm{O}$ espaço nacional hoje parece uma peça corroída ao acaso da transformação tecno-econômica mundial acentuar-se.

O próprio conceito centro-periferia deve ser recolocado sobre novas bases. Se antes a periferia era caracterizada a partir de dois traços- especialização e heterogeneidade -, hoje, percebidos os problemas com o conceito inicial, pode-se dividir o centro capitalista a partir de três controles: sobre o processo de inovação tecnológica; sobre a moeda e a finança internacionalizada, pressupondo elevado poder industrial e sobre o poder político-militar. 
Conseqüentemente, antes, como agora, em qualquer contexto de transformação e reavaliação, a ousadia de gerar interpretações em tempo real corre o risco de ser atropelada pelas próprias mudanças. Por isso, ao avaliar as contribuições e problemas da Antiga e da Nova CEPAL, é obrigatório levar em conta seu ambiente, o "entorno histórico" onde se criaram os modelos explicativos.

Quanto aos tempos atuais, é preciso afirmar mais um mérito ainda à Antiga CEPAL. O fenômeno que hoje salta aos nossos olhos, o debilitamento do Estado Nacional, significa, também, o enfraquecimento da própria democracia, na medida em que a nação é o único espaço onde se pode construir o acesso concreto e a intervenção das classes dominadas. Ou seja, o desmanche do Estado Nacional pode significar o desmanche da soberania do povo. Assim, os antigos cepalinos, ao lutarem pelo desenvolvimento dos países, tentando resgatar para a dignidade parte da população excluída, tentavam construir também Estados Nacionais mais fortes e, portanto, mais porosos à construção de espaços democráticos.

Mesmo assim, e por tudo o que já foi dito, a CEPAL ousou pensar nossa realidade. Tal ousadia, pouco valorizada entre os dados do poder na periferia, é fundamental para nós, como arma necessária para empreender mudanças sociais. Por isso mesmo, ela, a CEPAL, enquanto ousar, será sempre muito bem-vinda.

\section{REFERÊNCIAS BIBLIOGRÁFICAS}

BIElSCHOWSKY, Ricardo. Cinqüenta Anos de Pensamento na CEPAL. I. Ed. Rio de Janeiro: Record, 200o. (2 vol.).

BIELSCHOWSKY, Ricardo. Evolución de las Ideas de la CEPAL. I. Ed. Santiago: CEPAL, 1998. Disponível em <http://www.cepal.org〉. Acesso em jul. de 2007.

CANO, W. América Latina : do desenvolvimento ao neoliberalismo. In : FIORI, J. L. (org.). Estados e moedas no desenvolvimento das nações. Petrópolis : Vozes, 1999.

CARDOSO, Fernando Henrique e FALETTO, Enzo. Dependência e desenvolvimento na América Latina. Rio de Janeiro: Zahar, 1970. 
CEPAL. Transformación Productiva con Equidade: la tarea prioritária Del desarrollo de América Latina y El Caribe en los años noventa. Santiago: CEPAL, 199o. Disponível em $\langle$ http://www.cepal.org〉. Acesso em jul. de 2007.

FURTADO, Celso. A Fantasia Organizada. São Paulo: Paz e Terra, 1985.

FURTADO, Celso. Brasil: a construção interrompida. Rio de Janeiro: Paz e Terra, 1992.

FURTADO, Celso. O capitalismo Global. São Paulo: Paz e Terra, 1998.

GOLDENSTEIN, Lídia. Repensando a dependência. Rio de Janeiro: Paz e Terra, 1994.

GUIMARÃES, Samuel Pinheiro. Quinhentos anos de periferia: uma contribuição ao estudo da política internacional. 4. ed. Porto Alegre/Riode Janeiro: Ed. da UFRGS/Contraponto, 2002.

IANNI, Octávio. O labirinto latino-americano. Petrópolis, RJ: Vozes, I993.

JAGUARIBE, Helio. Brasil: alternativas e saída. São Paulo: Paz e Terra, 2002.

MELLO, Celso D. de Albuquerque. Curso de direito internacional público. 13. ed. rev. e aum. Rio de Janeiro: Renovar, 20or.

MELLO, José Manoel Cardoso. A contra-Revolução Liberal-Conservadora e a Crítica Latino-Americana. In: Tavares e Fiori (orgs). Poder e Dinheiro. Petrópolis: Editora Vozes, 1997.

MELlO, José Manoel Cardoso. O capitalismo Tardio. 8. Ed. São Paulo: Brasiliense, I99I.

MENEZES, Wagner (Coord.). Estudos de direito internacional. Curitiba: Juruá, v. III, 2005 .

NEGRÃO, José J. Para conhecer o neoliberalismo, São Paulo, Publisher Brasil, I998. Disponível no endereço eletrônico $\langle w w w . u n b . b r / a c s / a c s w e b\rangle$. Acesso em agosto de 2007.

OLIVEIRA, Francisco. A Economia Brasileira: Crítica à Razão Dualista. Estudos Cebrap. São Paulo, n.2, outubro, 1972.

PASSET, René. Economia: da unidimensionalidade à transdisciplinaridade. In a Religação dos Saberes: o desafio do século XXI/ idealizadas e dirigidas por Edgar Morin; tradução e notas, Flávia Nascimento, $2^{-}$ed. Rio de Janeiro: Bertrand Brasil, 2002.

PETRAS, James. Império e políticas revolucionárias na América Latina . Tradução de Carmem Cristina Cacciacarro. São Paulo: Xamã, 2002. 
PINTO, Anibal. Concentración del Progreso Técnico y de SUS Frutos en El Desarrollo Latinoamericano. El Trimestre Económico. México D.F;. n. I25, enero-marzo, 1965. Disponível em <http://www.cepal.org $>$. Acesso em jul. de 2007.

PREBISCH, Raul. El desarrollo econômico de America Latina y algunos de SUS principales problemas. Boletin Económico de América Latina, VIII, I962.

PREBISCH, Raul. O desenvolvimento da América Latina e seus principais problemas, Revista Brasileira de Economia, ano 3, no.3, Rio de Janeiro: Fundação Getúlio Vargas, setembro de 1949 .

RODRIGUEZ, Octavio et al., CEPAL: Velhas e Novas Idéias. Economia e Sociedade. Campinas, n. 5, p. 79-109, dezembro, 1995 .

RODRIGUEZ, Octavio. Teoria do Subdesenvolvimento da CEPAL. I. Ed. Rio de Janeiro: Forense Universitária, 1981.

SAMPAIO JR, Plínio. Entre a Nação e a Barbárie. Campinas. IE, 1997.

SANTOS, Luís Cláudio Villafañe Gomes. O império e as repúblicas do Pacífico: as relações do Brasil com Chile, Bolívia, Peru, Equador e Colômbia (1822-1889). Curitiba: Ed. da UFPR, 2002.

TAVARES, Maria da Conceição. La Cepal y la integración económica de América Latina. In: Revista de La Cepal no extraordinário Cepal so años, reflexiones sobre América Latina y el Caribe. Octubre, 1998. 